\title{
Application of Nanotechnology in Food Packaging
}

\author{
$\underline{\text { Asadi, G. }}{ }^{\text {a }}$, Mousavi , M. ${ }^{\text {b }}$ \\ a Department of Food Science and Technology, Science and Research Branch, Islamic \\ Azad University ,Tehran, Iran, E-mail : asadi@sr.iau.ac.ir \\ ${ }^{\mathrm{b}}$ College of Agriculture, University of Tehran, Department of Biosystems,Karaj, Iran
}

\begin{abstract}
Nanotechnology enables the designers to alter the structure of the packaging materials on the molecular scale, to give the materials desired properties. Simple traditional "packing" is to be replaced with multi-functional intelligent packaging methods to improve the food quality thanks to the application of nanotechnology in this field. With different nanostructure, the plastics can obtain various gas/water vapor permeability to fit the requirements of reserving fruit, vegetable, beverage and other foods. By adding nanoparticles, people can also produce bottles and packages with more light resistance, stronger mechanical and thermal performance, and less gas absorption. These properties can significantly increase the shelf life, efficiently preserve flavor \& color, and facilitate transportation \& usage. Further, nanostructured film can effectively prevent the food from the invasion of bacteria and microorganism and ensure the food safety. With embedded nanosensors in the packaging, consumers will be able to "read" the food inside. Sensors can alarm us before the food goes rotten or can inform us the exact nutrition status contained in the contents. nanotechnology is going to change the fabrication of the whole packaging industry. Self-assembly will reduce the fabrication costs and infrastructure. More flexible packaging methods will provide the consumers with fresher and customized products.
\end{abstract}

Key words : Nanotechnology, Nano structure ,Nano particles, Intelligent packaging

\section{Introduction}

Nanotechnology is an exciting and rapidly emerging technology allowing us to manipulate and create materials and structures at the molecular level, often atom by atom into functional structures having nanometer dimensions.. This will make products cheaper, production more efficient and more sustainable through using less water and chemicals.

Producing less waste and using less energy is a central concern of food manufacturers, and the drive towards production efficiency is likely to continue to boost nanotechnology funding.

Nanoscale biotech and nano-bio-info will have big impacts on the food and food-processing industries. The future belongs to new products, new processes with the goal to customize and personalize the products.

More than 180 applications are in different developing stages and a few of them are on the market already. The nanofood market is expected to surge from $2.6 \mathrm{bn}$. US dollars today to 7.0 bn. US dollars in 2006 and to 20.4 bn. US dollars in 2010. More than 200 Companies around the world are today active in research and development. USA is the leader followed by Japan and China. By 2010 Asian with more than 50 percent of the world population will be the biggest market for Nanofood with the leading of China (Moraru et al.,2003).

\section{Applications for food and beverage packaging}

Today, food-packaging and monitoring are a major focus of food industry-related nanotech R\&D. Packaging that incorporates nanomaterials can be "smart," which means that it can respond to environmental conditions or repair itself or alert a consumer to contamination and/or the presence of pathogens. According to industry analysts, the current US market for 
"active, controlled and smart" packaging for foods and beverages is an estimated $\$ 38$ billion and will surpass $\$ 54$ billion by 2008 (Donald , 2004).

Chemical giant Bayer produces a transparent plastic film (called Durethan) containing nanoparticles of clay. The nanoparticles are dispersed throughout the plastic and are able to block oxygen, carbon dioxide and moisture from reaching fresh meats or other foods. The nanoclay also makes the plastic lighter, stronger and more heat resistant.

Today, Nanocor, a subsidiary of Amcol International Corp., is producing nanocomposites for use in plastic beer bottles that give the brew a six-month shelf-life. By embedding nanocrystals in plastic, researchers have created a molecular barrier that helps prevent the escape of oxygen. Nanocor and Southern Clay Products are now working on a plastic beer bottle that may increase shelf-life to 18 months.

Kodak, best known for producing camera film, is using nanotech to develop antimicrobial packaging for food products that will be commercially available in 2005.Kodak is also developing other 'active packaging,' which absorbs oxygen, thereby keeping food fresh.

Scientists at Kraft, as well as at Rutgers University are working on nano-particle films concentration and other packaging with embedded sensors that will detect food pathogens. Called "electronic tongue" technology, the sensors can detect substances in parts per trillion and would trigger a color change in the packaging to alert the consumer if a food has become contaminated or if it has begun to spoil (Anonymous ,2004).

Researchers in the Netherlands are going one further to develop intelligent packaging that will release a preservative if the food within begins to spoil. This "release on command" preservative packaging is operated by means of a bio switch developed through nanotechnology.

Developing small sensors to detect food-borne pathogens will not just extend the reach of industrial agriculture and large scale food processing. In the view of the US military, it's a national security priority. With present technologies, testing for microbial food-contamination takes two to seven days and the sensors that have been developed to-date are too big to be transported easily. Several groups of researchers in the US are developing biosensors that can detect pathogens quickly and easily, reasoning that "super sensors" would play a crucial role in the event of a terrorist attack on the food supply ((Moraru et al.,2003).

RFid tags could be used on food packaging to perform relatively straightforward tasks, such as allowing cashiers in supermarkets to tally all of a customer's purchases at once or alerting consumers if products have reached their expiration dates. RFid tags are controversial because they can transmit information even after a product leaves the supermarket. Privacy advocates are concerned that marketers will have even greater access to data on consumerbehavior. Wal-Mart in the US and TESCO in the UK have already tested RFid tagging on some products in some stores.

The tagging of food packages will mean that food can be monitored from farm to fork during processing, while in transit, in restaurants or on supermarket shelves and eventually, even after the consumer buys it. Coupled with nanosensors, those same packages can be monitored for pathogens, temperature changes, leakages, etc (Scott , 2002).

\section{References}

Anonymous (2004).Down on the Farm: the Impact of Nano-Scale Technologies on Food and Agriculture, ETC Group Report.

Donald, A.(2004).Food for thought. Nature Materials ,3,578-581

Moraru, C., Panchapakesan ,C,Huang Q.,Takhistov P.(2003).Nanotechnology: A new frontier in food science. Food Technology ,57, 25-27

Scott, A.(2002).BASF takes big steps in small tech, focusing on nanomaterials. Chemical Week.164,1-45 